
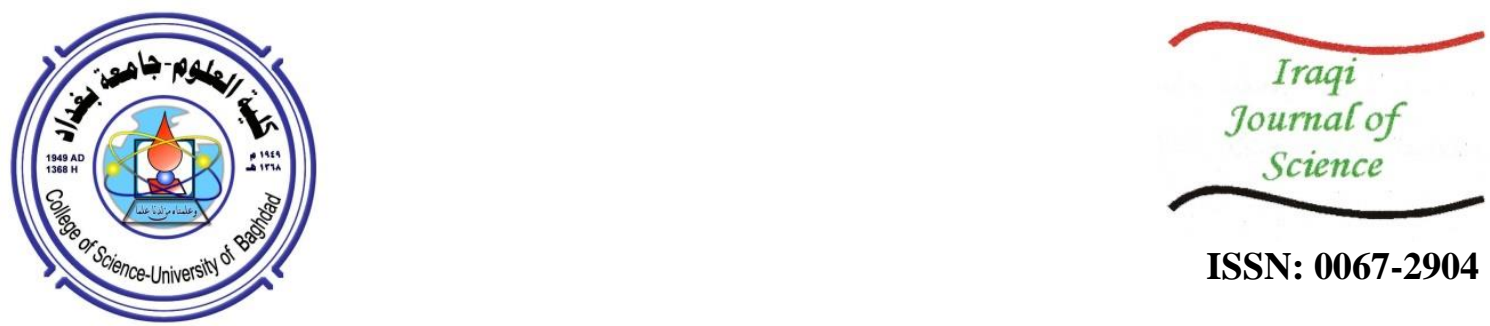

ISSN: 0067-2904

\title{
Removal of Aniline Blue from Textile Wastewater using Electrocoagulation with the Application of the Response Surface Approach
}

\author{
Mohammed A.Atiya ${ }^{1}$, Mohanad J. M-Ridha ${ }^{2}$, Meqat A.Saheb ${ }^{3}$ \\ ${ }^{1}$ Department of Biochemical Engineering, College of Engineering, University of Baghdad, Baghdad, Iraq \\ ${ }^{2}$ Department of Engineering Environmental, College of Engineering, University of Baghdad, Baghdad, Iraq \\ ${ }^{3}$ Department of Engineering Biochemical, College of Engineering, University of Baghdad, Baghdad, Iraq
}

Received: 23/10/2019

Accepted: $21 / 1 / 2020$

\begin{abstract}
This paper investigated the treatment of textile wastewater polluted with aniline blue (AB) by electrocoagulation process using stainless steel mesh electrodes with a horizontal arrangement. The experimental design involved the application of the response surface methodology (RSM) to find the mathematical model, by adjusting the current density $(4-20 \mathrm{~mA} / \mathrm{cm} 2)$, distance between electrodes $(0.5-3 \mathrm{~cm})$, salt concentration $(50-600 \mathrm{mg} / \mathrm{l})$, initial dye concentration $(50-250 \mathrm{mg} / \mathrm{l}), \mathrm{pH}$ value $(2-12$ ) and experimental time $(5-20 \mathrm{~min})$. The results showed that time is the most important parameter affecting the performance of the electrocoagulation system. Maximum removal efficiency $(96 \%)$ was obtained at a current density of 20 $\mathrm{mA} / \mathrm{cm} 2$, distance between electrodes of $1.75 \mathrm{~cm}$, salt concentration of $462.5 \mathrm{mg} / \mathrm{l}$, dye concentration of $50 \mathrm{ppm}, \mathrm{pH}$ value of 7 , and time duration of $15 \mathrm{~min}$. On the other hand, the electrocoagulation efficiency was directly proportional to current density, salt concentration, and contact time, while it was inversely proportional to dye concentration. Isotherm experiments showed that the equilibrium data are best fitted to Freundlich isotherm and sips isotherm; whereas the kinetics results showed that the rate of adsorption followed the pseudo-second-order with an R2 value of 98 $\%$.
\end{abstract}

Keywords: Electrocoagulation, Aniline blue dye, RSM, adsorption isotherm, adsorption kinetics

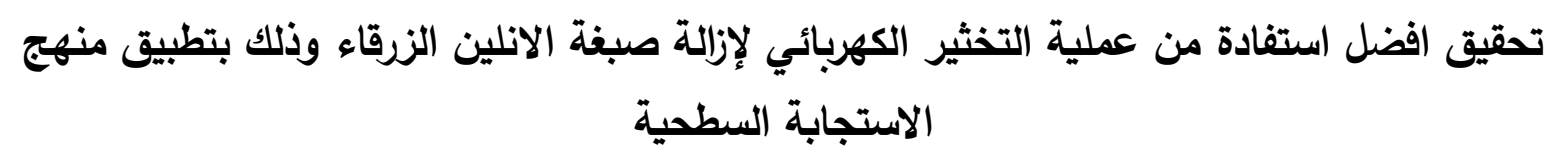

\footnotetext{
عحم عبد عطية 1**, مهند جاسم كحم رضا 2,ميقات اياد صاحب 3

1قسم هندسة الكيمياء الاحيائية , كلية الهندسة الخوارزمي , جامعة بغداد, بغداد, العراق هاق

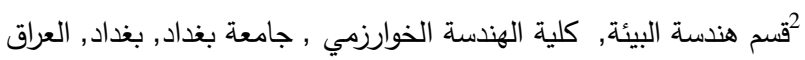

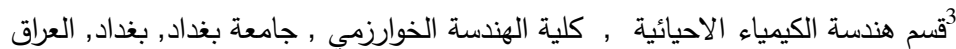

بحثت هذه الدراسة معالجة مياه الصرف النسيجي بطريقة التخثر الكهربائي وباستخدام اقطاب الحديد

المرتبة افقياً. تضدنت التجارب تطبيق منهج الاستجابة السطحية لإيجاد موديل رياضي وذلك من خلال ضبط بطي
}

*Email: meqat.ayad@yahoo.com 


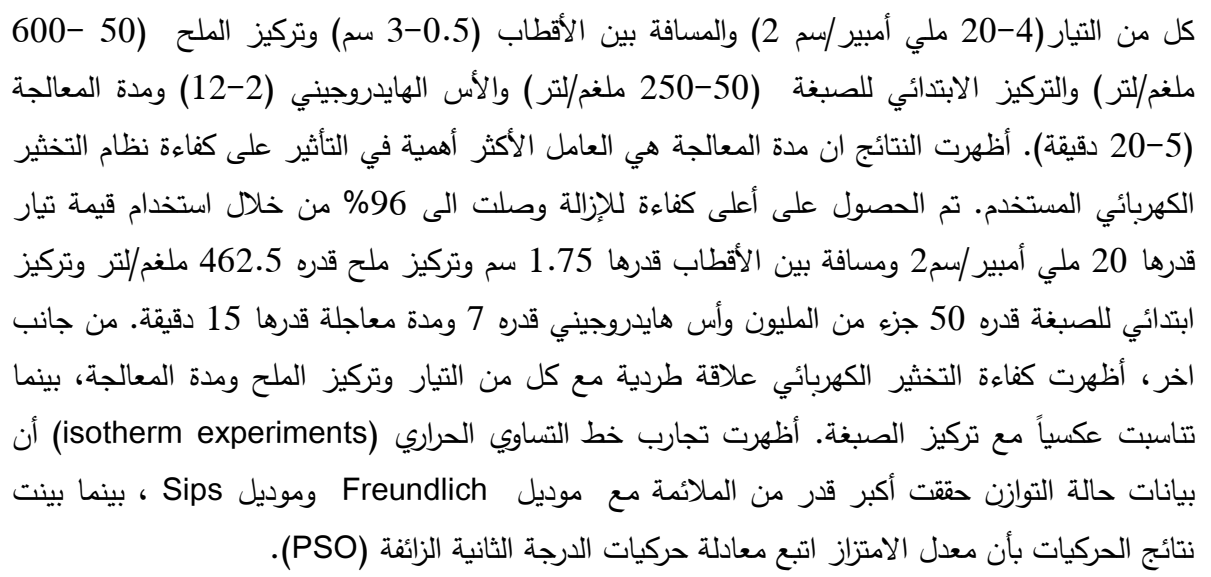

\section{Introduction}

For optimal results in the textile industry, it is extremely essential to dye the textile properly and to perform an efficient finishing process. These activities consume a considerable amount of water and produce wastewater that is characterized by intense colors along with high levels of suspended particles, $\mathrm{pH}$, chemical oxygen demand (COD), and biological oxygen demand (BOD) [1]. These processes utilize about 10,000 types of dyes and pigments [2], where 1 to $15 \%$ of the dye is released as wastewater. This dye-containing wastewater is harmful to human and aquatic life because most kinds of these dyes might cause toxicity, cancer, or mutations to living organisms [3]. Therefore, there is a growing requirement for intensive treatment of wastewater in order to protect the environment from these harmful chemicals and dyes, because of their stability, low bio degradability, and high toxicity [4].

Adsorption, precipitation, photodegradation, biodegradation, membrane filtration, chemical coagulation, and electrocoagulation are the most commonly used techniques to treat the colored wastewater and solve the problem of industrial wastes [5].

Adsorption and precipitation are very time consuming, expensive, and low efficient methods, with high sludge volume produced [6].

One of the most effective techniques is the use of chemical oxidation, e.g., using chlorine, to degrade the pollutants in waste water, although it produces certain toxic materials, including organochlorine compounds [7].

The use of $\mathrm{UV} / \mathrm{TiO} 2$ or $\mathrm{UV} / \mathrm{H} 2 \mathrm{O} 2$ in photooxidation is a very expensive process that requires adding other types of chemicals and, thus, results in secondary pollution processes [8].

While biodegradation is less expensive compared to the other approaches, it is considered as ineffective as a result of the toxic dyes that show inhibitory influences on bacterial growth [5].

Recently, electrocoagulation (EC) was proved as an electrochemical method with very effective solutions to overcome the main disadvantages of conventional processes in eliminating unwanted wastewater discharges.

In this study, the treatment efficiency of synthetic industrial textile wastewater was optimized using RSM by Design Expert 6.0 (trial version).

Response surface methodology adopts a statistical approach to optimize the parameters that are applied in the chemical operation, both at the theoretical and practical levels.

Researchers in this field applied this approach to achieve several aims; first, to develop a polynomial model of the second order. Second, to understand the influences of various factors along with their interplay on the final response. Third, to compare the individual significance of the factors involved. Forth, to optimize the entire process. Moreover, other advantages of this approach include the dramatic reduction of the overall number of experimental trials, which reduces both the time and the costs of the experiments.

\subsection{Isotherm Study}

Freundlich, Langmuir, Tempkin, Dubinin, and Sips isotherm models were used to investigate the adsorption model of experimental data and maximum uptake of pollutants from the aqueous phase to the solid phase $[4,9,10]$. Then, the most appropriate correlation for the equilibrium curves was determined. The suitability and acceptability of the isotherm equation to the equilibrium data were based on the values of the correlation coefficients $R^{2}$ which was estimated from linear regression. 


\subsubsection{Langmuir isotherm}

Langmuir isotherm is applied for homogeneous and monolayer adsorption. This model is based on two assumptions; first, that once a molecule occupies a site, no additional sorption takes place. Second, the forces of interaction between adsorbed molecules are negligible [11, 12]. The linear form of this model can be described by Eq. 1:

$$
\frac{1}{q e}=\frac{1}{Q 0}+\frac{1}{b * Q 0 * C e}
$$

Ce represents the concentration of the solute in the bulk solution $(\mathrm{mg} \mathrm{L}-1)$ that achieves equilibrium. qe is the amount of solute adsorbed per unit weight of the adsorbent at equilibrium (mg $\mathrm{g}-1)$. $\mathrm{b}$ is the constant related to the free energy of adsorption $(\mathrm{L} \mathrm{mg}-1)$. Q0 is the maximum adsorption capacity (mg g-1).

\subsubsection{Freundlich isotherm}

This isotherm describes reversible, non-ideal, and heterogeneous adsorption and can be applied to multilayer adsorption. Moreover, this model is not restricted to the formation of the monolayer [12, 13]. The linear form of this model is shown in Eq.2:

$$
\ln q_{e}=\ln K_{F}+\frac{1}{n} \ln C_{e}
$$

$\mathrm{K}_{\mathrm{F}}$ is the Freundlich constants related to the adsorption capacity and $\mathrm{n}$ is the intensity of adsorption.

\subsubsection{Tempkin isotherm}

This isotherm depends on the hypothesis that the sorption's free energy is the result of a change in the surface coverage. It also considers the interplay between sorbent and adsorbent $[14,13]$ The Tempkin isotherm is represented in Eq. 3:

$$
\begin{gathered}
q_{e}=B \ln K_{T}+B \ln C_{e} \\
B=\frac{R T}{b}
\end{gathered}
$$

$\mathrm{T}$ is the absolute temperature at $298 \mathrm{~K} . K_{T}$ is the maximum binding energy $(\mathrm{L} / \mathrm{g})$. B is constantly related to the heat of sorption $(\mathrm{J} / \mathrm{mol})$

$\mathrm{b}$ is Temkin isotherm constant, which indicates the adsorption potential of the adsorbent. $\mathrm{R}$ is the universal gas constant $(8.314 \mathrm{~kJ} / \mathrm{mol})$

\subsubsection{Dubinin-Radushkevich isotherm}

The $\mathrm{D}-\mathrm{R}$ sorption isotherm is applied to determine the nature of adsorption processes as physical or chemical and to estimate the heterogeneity of the surface energies [14], as calculated by Eq. 5

$$
\ln Q_{e}=\ln Q_{m}-\beta \varepsilon^{2}
$$

where $\varepsilon$ is known as Polanyi potential

$$
\varepsilon=R T \ln \left(1+\frac{1}{C_{e}}\right)
$$

\subsubsection{Sips isotherm}

This model combines Freundlich and Langmuir isotherms and is applied to predict the heterogeneous adsorption systems that accompany the Freundlich model. At low Ce, it reduces to Freundlich isotherm while, at high $\mathrm{Ce}$, it predicts monolayer adsorption characteristics of Langmuir isotherm [15].

The Sips model is represented in Eq. 7:

$$
q_{e q}=\frac{Q_{\max }\left(K_{S} C_{e}\right)^{n}}{1+\left(K_{S} C_{e}\right)^{n}}
$$

The model has the following linear form:

$$
\frac{1}{q_{e}}=\frac{1}{Q_{\max }}+\frac{1}{Q_{\max } K_{s}}\left(\frac{1}{C_{e}}\right)^{1 / n}
$$

$K_{S}(1 / \mathrm{mg})$ is Sips equilibrium constant. $Q_{\max }(\mathrm{mg} / \mathrm{g})$ is the maximum adsorption capacity. $\mathrm{n}$ is the dimensionless heterogeneity factor between 0 and 1 


\subsection{Adsorption Kinetic Study}

Kinetics investigations take an essential part in the determination of the order of reaction as well as the rate constant, with the latter being of high importance in designing wastewater treatment facilities. It is employed to determine the kind of reaction rates in this designing process. Thus, the rate constant is very significant in the design of wastewater treatment units. It is essential to know the type of reaction rates for designing a wastewater treatment unit. To estimate the adsorption mechanism, three models of kinetics are used, represented by the pseudo first order, pseudo-second-order, and Elovich equation mode.

\subsubsection{Pseudo first order}

The adsorption rate for this kinetic is given by Eq. (9)

$$
\ln \left(q_{e}-q_{t}\right)=\ln q_{e} \quad-k_{1} t
$$

qe is the concentration of the dye adsorbed $(\mathrm{mg} / \mathrm{g})$ at equilibrium. $q_{t}$ is the amount of dye adsorbed at any time t. $K_{1}$ is the rate constant for pseudo-first-order kinetics $\left(\mathrm{min}^{-1}\right)$ [13].

\subsubsection{Pseudo second order}

Pseudo-second order is expressed by Eq. (10)

$$
\frac{t}{q_{t}}=\frac{1}{k_{2} q_{e}^{2}}+\frac{t}{q_{e}}
$$

where $K_{2}$ (gm/mg.min) is pseudo second order constant [12].

\subsubsection{Elovich equation}

The linear form of Elovich kinetic equation is expressed by Eq. (11):

$$
q_{t}=\left(\frac{1}{\beta}\right) \ln (\beta \alpha)+\left(\frac{1}{\beta}\right) \ln (\mathrm{t})
$$

where $q_{t}$ represents the amount of dye adsorbed at time t, $\beta$ is the desorption constant, and $\alpha$ is the initial adsorption rate.

\section{Materials and Methods}

\subsection{Preparation of the Dye}

The stock solution of aniline blue dye (ABD) was purchased from BDH, England. $1 \mathrm{gm}$ of the powder was dissolved in $1000 \mathrm{ml}$ distilled water. By diluting the stock solution, different concentrations $(50-250 \mathrm{mg} / \mathrm{L})$ of the dye were prepared. The characteristics of the dye are presented in Table-1.

Table 1-Characteristics of aniline blue [16]

\begin{tabular}{|c|c|}
\hline Spectrum wavelength & $595 \mathrm{~nm}$ \\
\hline Molecular weight & $737.724 \mathrm{~g} / \mathrm{mol}$ \\
\hline Physical state at $20^{\circ} \mathrm{C}$ & Solid \\
\hline Solubility in water & Soluble in water \\
\hline Color & Black \\
\hline Odor & Odorless \\
\hline
\end{tabular}

\subsection{Electrocoagulation Unit}

The experimental design is demonstrated in Figure-1. The electrocoagulation unit is composed of an electrochemical reactor with stainless steel mesh electrode $\left(10 \mathrm{~cm}^{*} 10 \mathrm{~cm}\right)$. The current density was measured using a DC-regulated power supply (China, 2009). $\mathrm{pH}$ was brought to the desired value by using $\mathrm{NaOH}$ or $\mathrm{H} 2 \mathrm{SO} 4$, while conductivity was adjusted by $\mathrm{NaCl}$. Before and at the end of each run, electrodes were washed thoroughly with water and dipped in $\mathrm{HCl}$ solution.

A UV-Vis spectrophotometer (shimadzu, 1800) at the wavelength of $595 \mathrm{~nm}$ was used to determine the color removal efficiency, which was calculated as in Eq. 12:

$$
\text { Color removal efficiency }(\%)=\frac{(C o-C)}{C o} * 100
$$

where $\mathrm{Co}$ is the dye concentration prior to electrocoagulation, while $\mathrm{C}$ is the dye concentration following the electrocoagulation [17]. 


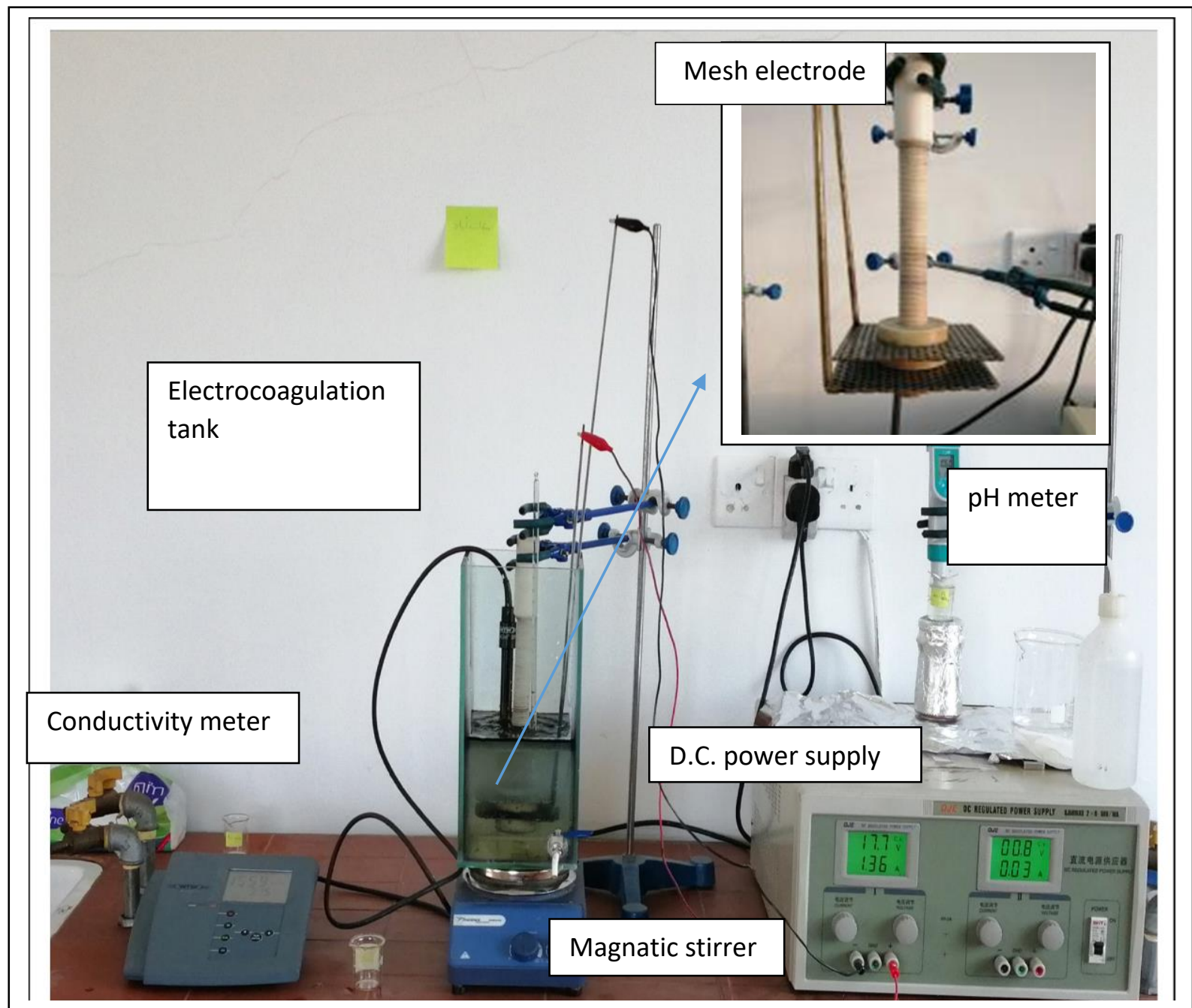

Figure 1-The electrocoagulation unit

Table 2-Experimental range and levels of an independent process variable

\begin{tabular}{|l|l|l|l|l|}
\hline \multicolumn{2}{|l}{ Independent variable } & factor & \multicolumn{2}{l|}{ Range and level } \\
\hline $\mathrm{X}_{\mathrm{i}}$ & & -1 & 0 & +1 \\
\hline Current density $\left(\mathrm{mA} / \mathrm{cm}^{2}\right)$ & $\mathrm{X}_{1}$ & 4 & 12 & 20 \\
\hline Distance between electrode $(\mathrm{cm})$ & $\mathrm{X}_{2}$ & 0.5 & 1.75 & 3 \\
\hline Salt concentration $(\mathrm{gm} / \mathrm{l})$ & $\mathrm{X}_{3}$ & 50 & 325 & 600 \\
\hline$\underline{\mathrm{pH}}$ & $\mathrm{X}_{4}$ & 2 & 7 & 12 \\
\hline Time $(\min )$ & $\mathrm{X}_{5}$ & 4 & 12 & 20 \\
\hline Dye concentration $(\mathrm{ppm})$ & $\mathrm{X}_{6}$ & 50 & 150 & 250 \\
\hline
\end{tabular}

\section{Results and Discussion}

Electrocoagulation kinetics results showed that the rate of adsorption followed the pseudo-secondorder with an R2 value of $98 \%$ and a maximum removal efficiency $96 \%$ obtained at a current density of $20 \mathrm{~mA} / \mathrm{cm} 2$, distance between electrodes of $1.75 \mathrm{~cm}$, salt concentration of $462.5 \mathrm{mg} / \mathrm{l}$, dye concentration of $50 \mathrm{mg} / \mathrm{l}, \mathrm{pH}$ value of 7 , and time duration of $15 \mathrm{~min}$.

On the other hand, when the previous method was compared with that of biosorption, the kinetics of aniline blue was found to obey pseudo-second order kinetic model $(\mathrm{R} 2=0.967)$, while the maximum biosorption of aniline blue was observed at the sorbent concentration of $1 \mathrm{~g} / \mathrm{L}$, initial $\mathrm{pH} 10$, temperature $30^{\circ} \mathrm{C}$, agitation rate $160 \mathrm{rpm}$, and initial dye concentration of $50 \mathrm{mg} / \mathrm{L}$ [18] . 
The experimental design was based on a central composite design (CCD), while the analysis of data was carried out using response surface methodology (RSM) in design Expert software. Box-Wilson method was used to assess the individual and combined influences of the operation parameters on the efficiency of color elimination [ 19 ].

The results were analyzed based on the RSM statistical approach and used to fit in a polynomial model of a second order. The response equation expressed below was employed in order to apply a correlation of the dependent factors to the independent ones [19].

Application of RSM offers the below demonstrated empirical correlation linking color removal efficiency (R1) and independent variables.

$$
\begin{array}{r}
\mathrm{R}_{1}=-17.13+4.130 \mathrm{X}_{1}+9.36 \mathrm{X}_{2}+0.34 \mathrm{X}_{3}+0.30 \mathrm{X}_{1} \mathrm{X}_{2}+-0.004 \mathrm{X}_{1} \mathrm{X}_{3}+-0.0031 \mathrm{X}_{2} \mathrm{X}_{3}+-0.067 \mathrm{X}_{1}^{2} \\
+-2.03 \mathrm{X}_{2}^{2}+-0.00036 \mathrm{X}_{3}^{2} \\
\mathrm{R}_{1}=32.06+-0.23 \mathrm{X}_{6}+19.32 \mathrm{X}_{4}+-1.73 \mathrm{X}_{5}+0.016 \mathrm{X}_{6} \mathrm{X}_{4}+0.0102 \mathrm{X}_{6} \mathrm{X}_{5}+-0.13 \mathrm{X}_{4} \mathrm{X}_{5}+-3.65 \mathrm{X}_{6}^{2}+- \\
1.11 \mathrm{X}_{4}^{2}+0.09 \mathrm{X}_{5}^{2}
\end{array}
$$

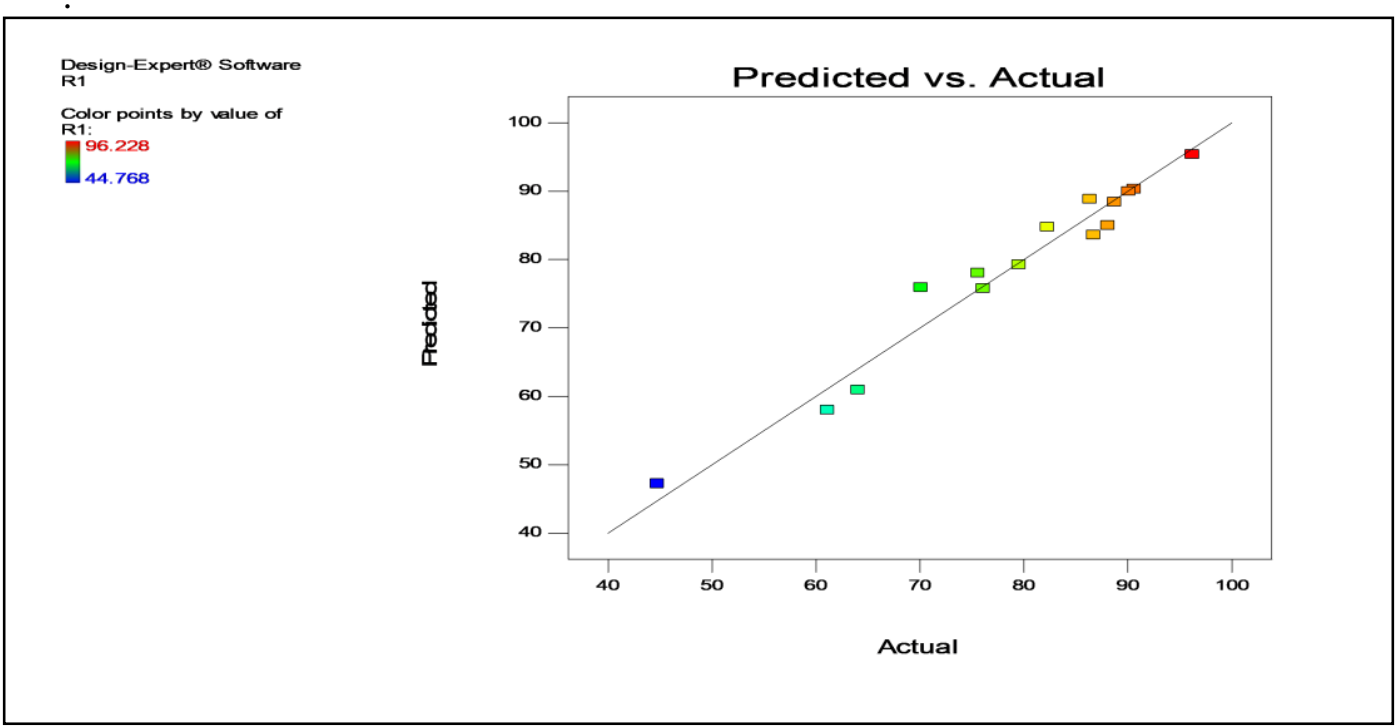

Figure 2-Actual and predicted values of removal efficiency from Eq.(13)

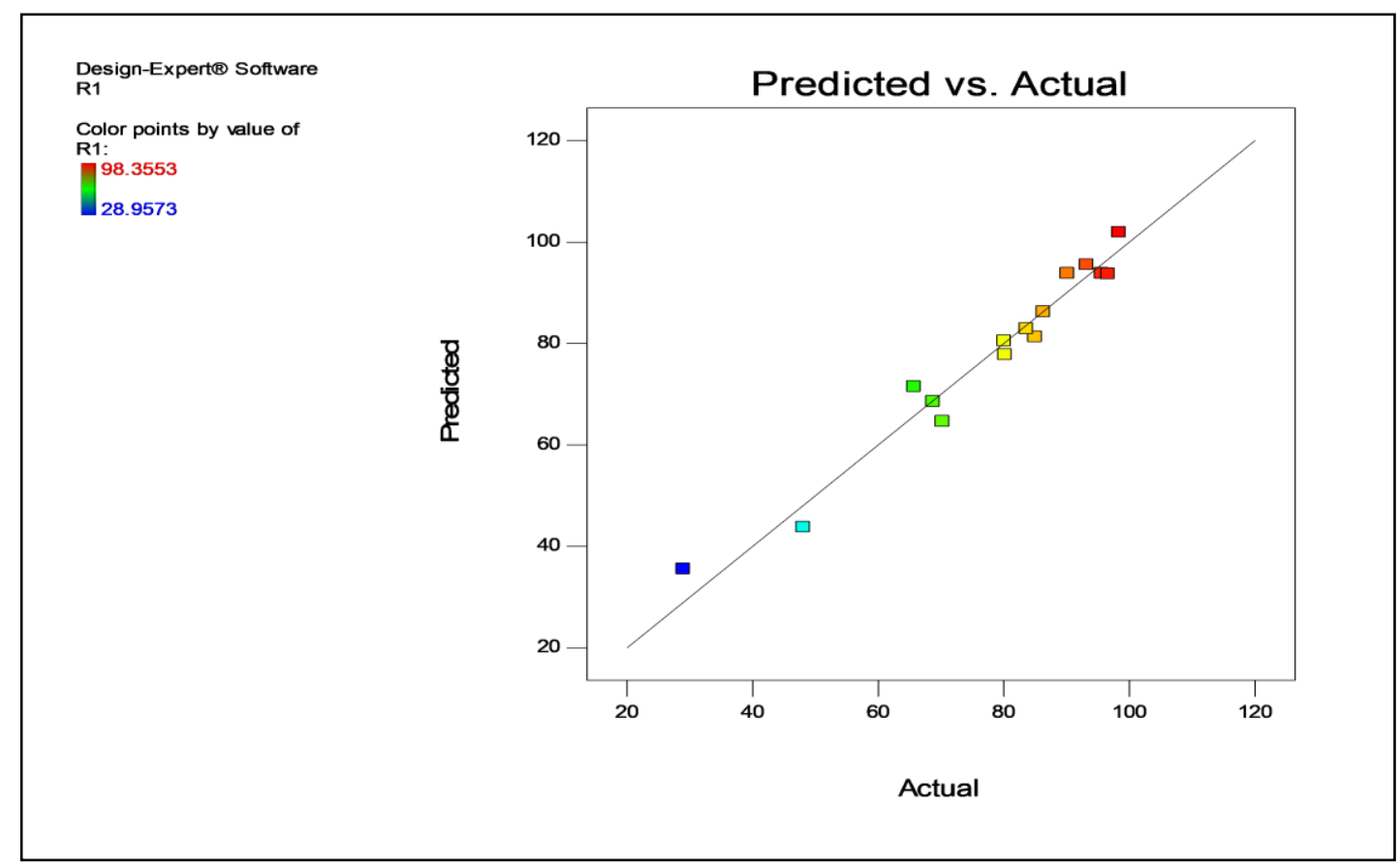

Figure 3-actual and predicted removal efficiency from Eq. (14) 
$\mathrm{R} 1$ value is predicted through Eqs 13 and 14. ANOVA results showed a good consistency between the efficiencies of color removal, giving less than 0.05 of probability of error (p) and a high R-squared value of $94 \%$, indicating the high correlation between the predicted and actual values.

\subsection{Effect of initial dye concentration}

Figure-4 shows the effects of aniline blue concentrations on the electrocoagulation efficiency. From these results, it was found that the removal efficiency at different dye concentrations (50-250 ppm) and optimum current density, salt concentration, and distance between electrodes $(20 \mathrm{~mA} / \mathrm{cm} 2$, $462 \mathrm{mg}$, and $1.75 \mathrm{~cm}$, respectively) was decreased as the initial dye concentration was increased. Based on the law of Faraday, at similar conditions of current, voltage, and time for the entire concentration range, $\mathbf{F e}^{+2}$ is released at constant amounts into the solution. Therefore, a similar amount of flocs is released within the solution. Flocs have a restricted capacity of adsorption and, thus, a certain quantity of flocs is only capable of adsorbing a certain quantity of dye molecules [20]. Hence, a limited quantity of flocs produced would not have a sufficient capacity for the adsorption of the entire amount of dye molecules, leading to reduction of efficiency.

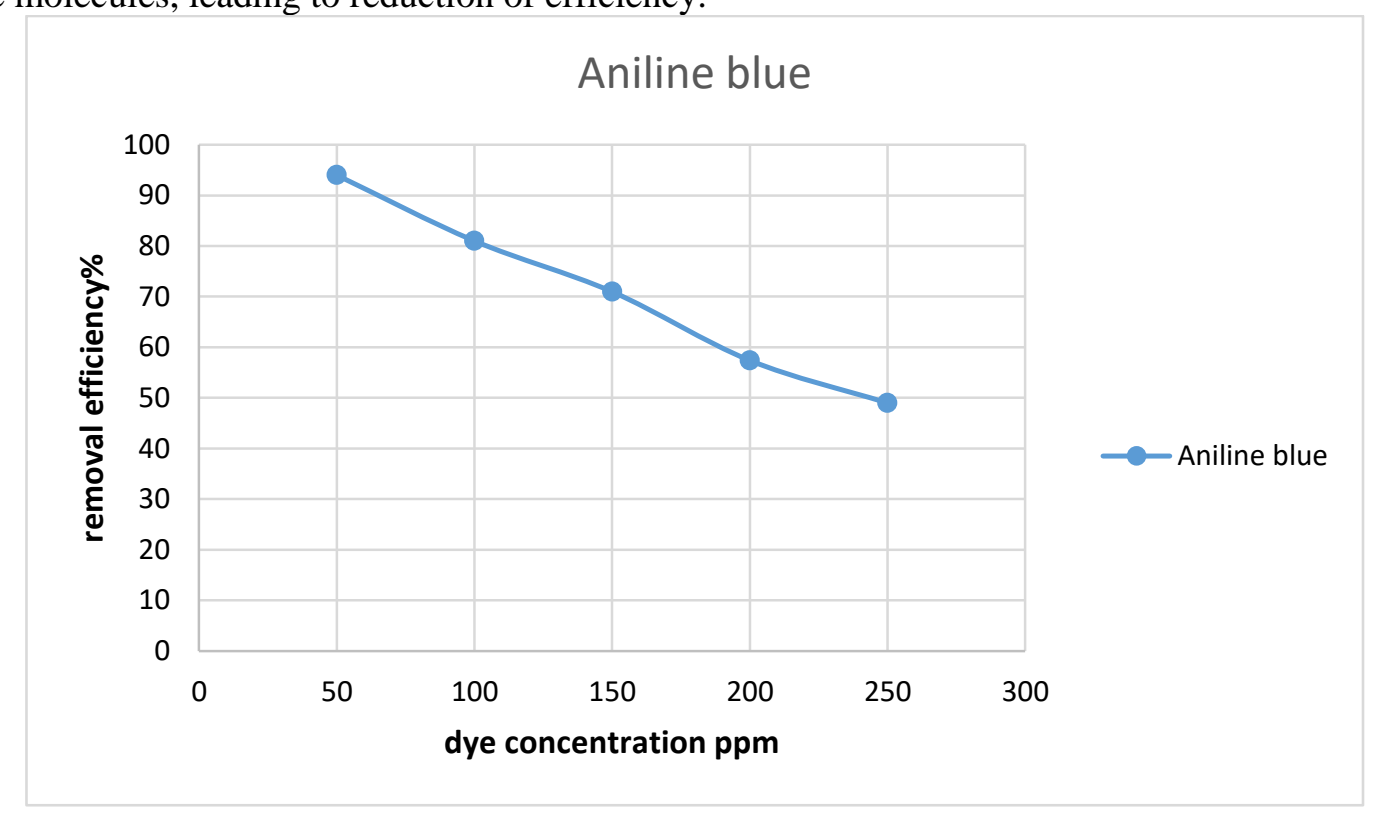

Figure 4-The effect of the concentration of aniline blue dye on the removal efficiency. Current density $20 \mathrm{~mA} / \mathrm{cm} 2$ at $20 \pm 2^{\circ} \mathrm{C}, \mathrm{pH}=7$, contact time $15 \mathrm{~min}$, salt conc. $462 \mathrm{ppm}$, and distance between electrodes $1.75 \mathrm{~cm}$.

\subsection{Effects of current density}

Figure-5 shows the effects of current density on the removal efficiency, which was increased from $54 \%$ to $93.1 \%$ by increasing current density within a range of $4-20 \mathrm{~mA} / \mathrm{cm} 2$. This can be attributed to an elevated level of $\mathbf{F e}^{+2}$ produced by the electrode, leading to increased flocs and hydroxyl radicals, as previously explained [7]. Furthermore, the elevated current density is associated with an elevated rate of bubble production and a reduced bubble size, which are considered as advantageous patterns as related to the efficiency of color removal by floc flotation, which is resulted from the decrease of cathodic reduction of $\mathbf{H}^{+}$to $\mathbf{H}_{2}$ [8]. 


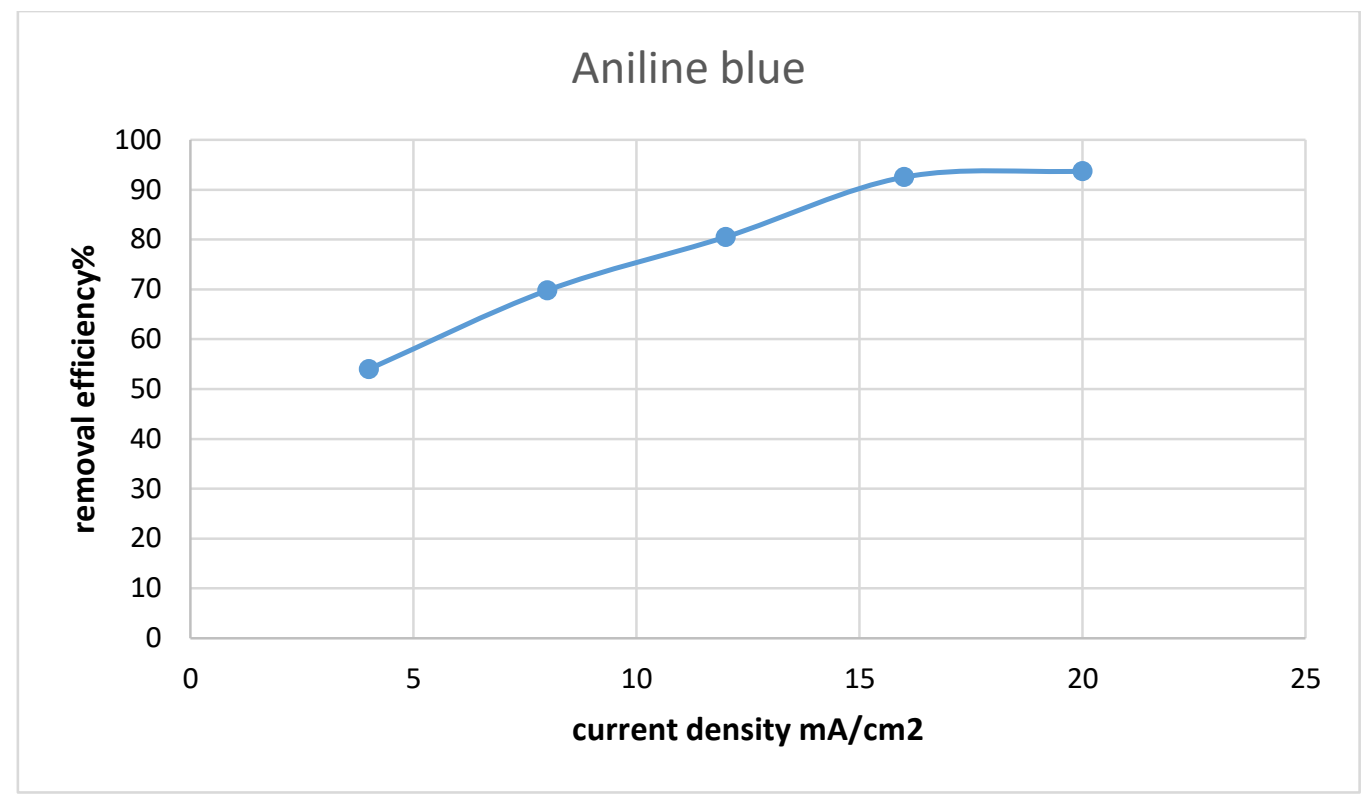

Figure 5-The effect of current density on the removal efficiency of $\mathrm{AB}$ dye at $20 \pm 2^{\circ} \mathrm{C}$, dye conc. 50 ppm, $\mathrm{pH}=7$, contact time $15 \mathrm{~min}$, salt conc. $325 \mathrm{ppm}$, and distance between electrodes $1.75 \mathrm{~cm}$.

\subsection{Effects of distance between electrodes}

The removal efficiency was low at distance $=0.5 \mathrm{~cm}$ and was increased with the increase in distance until reaching an optimum point. Thus, removal efficiency of the color is affected both positively and negatively by the distance separating one electrode from the other (Figure-6). In addition, it is predicted that the interaction between the dye and the hydroxyl polymers becomes lower as this distance increases. This implies that the reduced color removal efficiency is caused by reductions in local concentration and electrostatic attraction, as was previously proved [21]. The opposite is observed when an increase in the distance occurs, leading to a reduction in the speed of the ions movement as well as an increased chance for their aggregation, floc formation, and dye molecules adsorption. Thus, an association was observed between the higher distance between the electrodes and the greater removal efficiency of the polluting color. Such an association can be attributed to the fact that the produced metal hydroxides behave as flocs that eliminate the pollutants by sedimentation. The pollutants then undergo degradation by collision with each other due to high electrostatic attraction [22]. Consequently, a value of $1.75 \mathrm{~cm}$ was selected as an optimal distance between the electrodes.

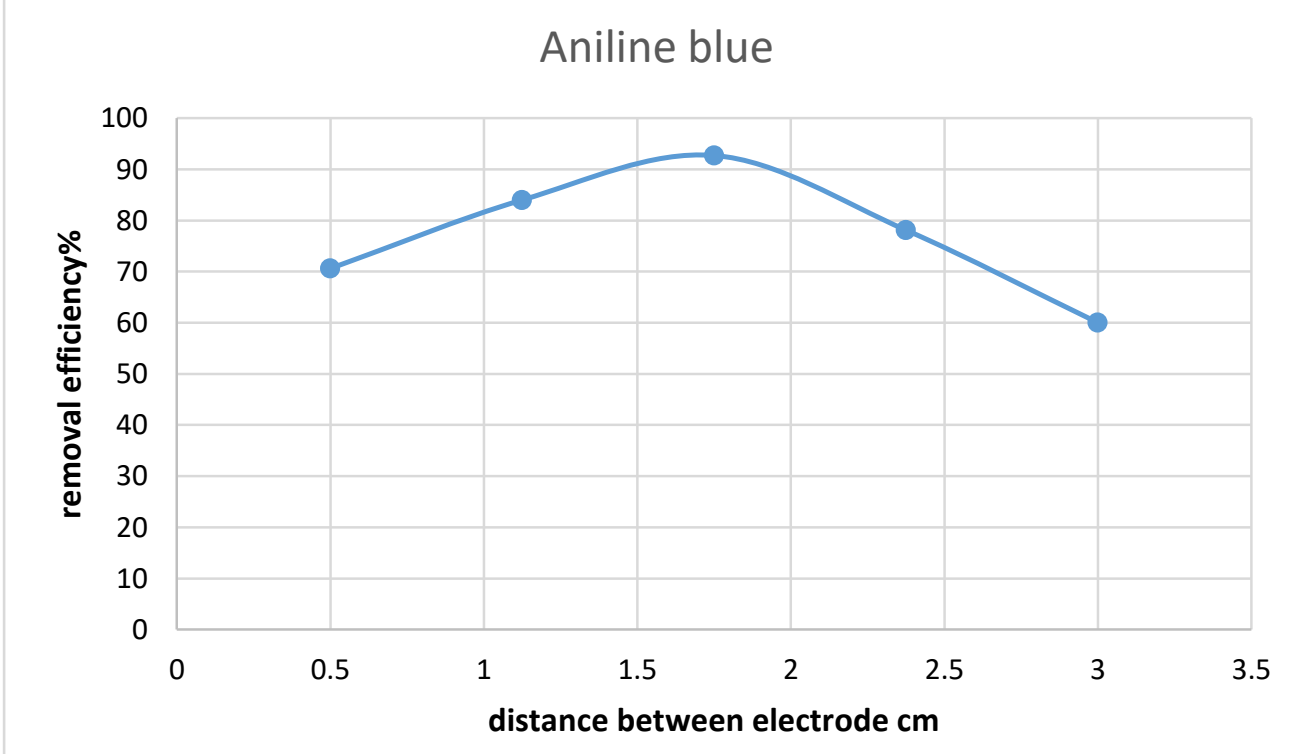

Figure 6-Effect of contact distance between electrodes on the percent removal of $\mathrm{AB}$ dye. Dye conc. $50 \mathrm{ppm}, \mathrm{pH}=7$, contact time $15 \mathrm{~min}$, salt conc. $325 \mathrm{ppm}$, current density $20 \mathrm{~mA} / \mathrm{cm} 2$. 


\subsection{Effects of salt $(\mathrm{NaCl})$ concentration}

Figure-7 shows the effects of salt concentration on the electrocoagulation efficiency. From this figure, it is clear that the removal of the dye at different salt concentrations $(50-600 \mathrm{ppm})$ was increased as the salt concentration was increased until reaching an optimum concentration, after which it was decreased. The improved dye elimination efficiency was caused by the increase in the conductivity, until a maximum level of $462 \mathrm{mg} / \mathrm{l}$ for $\mathrm{AB}$ [23]. Nevertheless, when sodium chloride concentration was elevated to $>462 \mathrm{mg} / \mathrm{l}$, a reduction in the removal efficiency occurred. Such an effect might be due to the events accompanying the constant value of voltage and the elevating concentrations of electrolytes. These events are represented by the elevated conductivity of the dye's solution and the reduced resistance. Hence, elevations in the levels of the applied current, the produced metallic hydroxide, and the efficiency of the removal are observed [24].

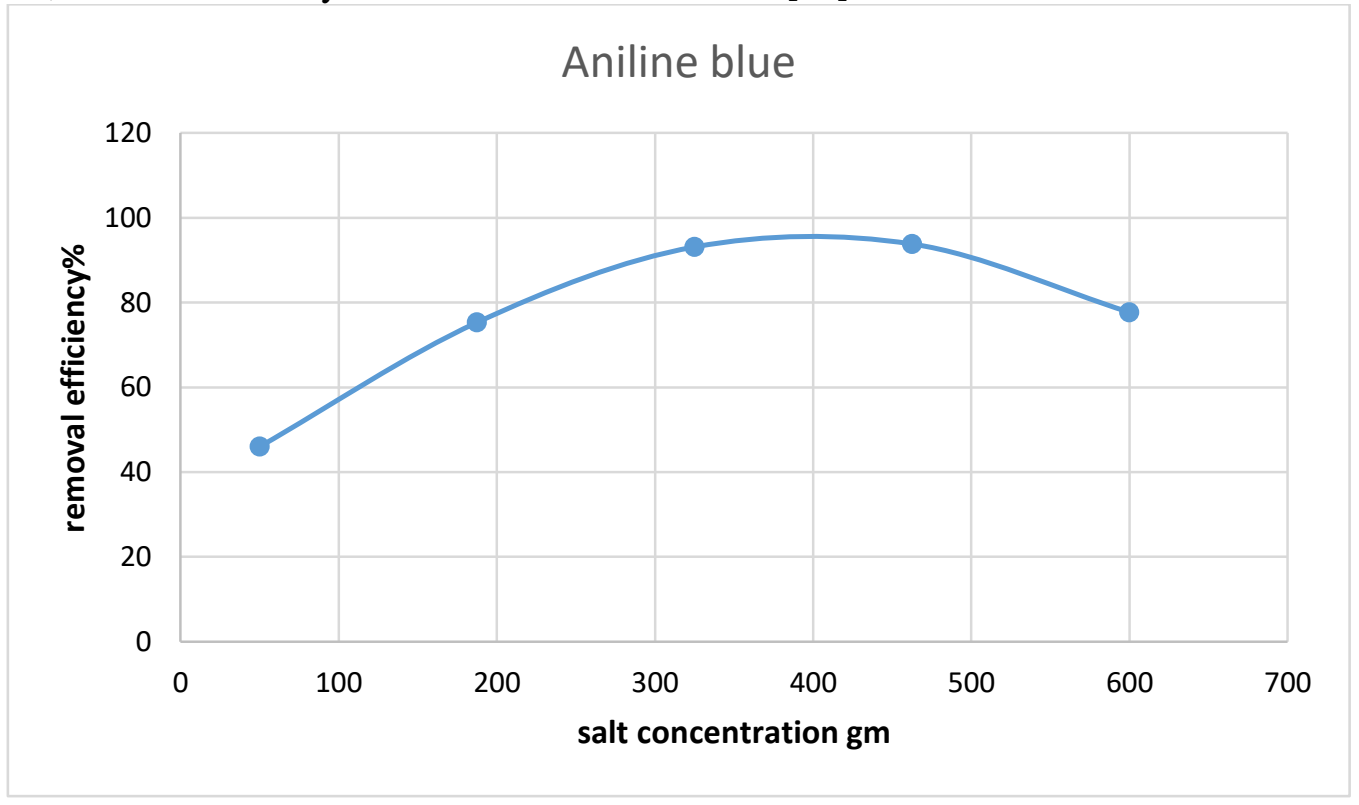

Figure 7-The effect of salt concentration on the removal efficiency of aniline blue. Current density 20 $\mathrm{mA} / \mathrm{cm} 2$ at $20 \pm 2^{\circ} \mathrm{C}, \mathrm{pH}=7$, contact time $15 \mathrm{~min}$, dye conc. $50 \mathrm{ppm}$, and distance between electrodes $1.75 \mathrm{~cm}$.

\subsection{Effects of $\mathrm{pH}$}

The effects of $\mathrm{pH}$ were studied at the acidic, moderate and basic media, in the range of 2-12, by adjusting the prepared wastewater using $\mathrm{NaOH}$ and $\mathrm{HCl}$ solutions (Fig 8). Removal efficiency percentage was elevated with the elevation in $\mathrm{pH}(2-7)$, achieving an optimal value which was followed by a reduction, with the overall range being $8-12 \%$. The formed ferrous ions undergo hydrolization and consequently produce, based on $\mathrm{pH}$ level, hydroxide ions and complexes. Hydroxide complexes are polymers with cations of strong charge, which act in destabilizing the negatively charged colloidal particles, leading to their aggregation and the construction of flocs [16]. The removal efficiency was enhanced as the $\mathrm{pH}$ value was increased (from 2to 7), due to the increased conductivity of the solution medium with increasing $\mathrm{pH}$. The maximum removal efficiency was obtained at $\mathrm{pH} 7$. Thus, this $\mathrm{pH}$ value can be considered as the optimal for achieving electrocoagulation, as it is the value at which the formation of most of the coagulants occurs [25]. At a pH value higher than 7, color removal efficiency was reduced, as $\mathrm{Fe}(\mathrm{OH}) 4-$ was the dominant form that is considered as a dissolving species with no ability of floc formation [26]. 


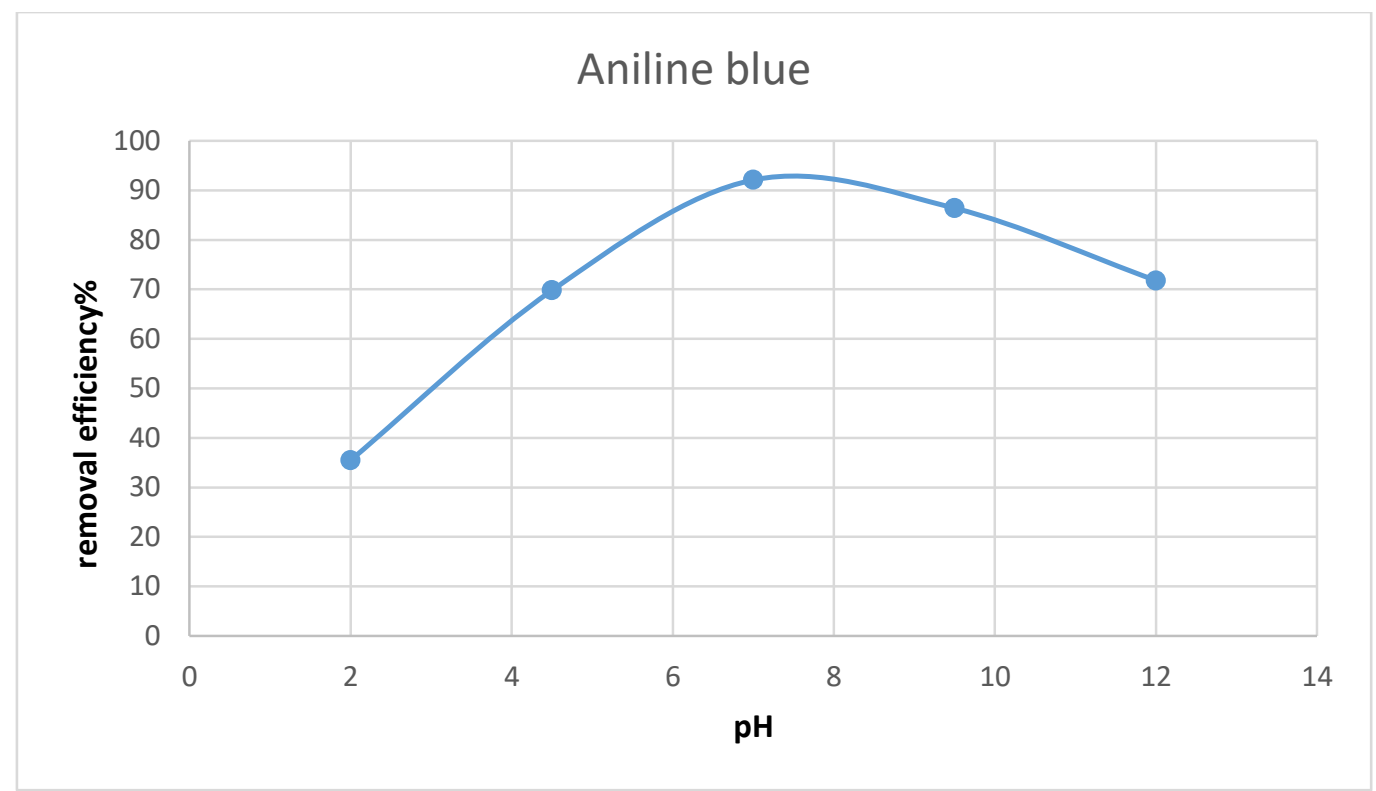

Figure 8-Effect of $\mathrm{pH}$ on the percentage removal of aniline blue dye. Current density $20 \mathrm{~mA} / \mathrm{cm} 2$ at $20 \pm 2^{\circ} \mathrm{C}$, dye conc. $50 \mathrm{ppm}$, contact time $15 \mathrm{~min}$, salt conc. $462 \mathrm{ppm}$, and distance between electrodes $1.75 \mathrm{~cm}$.

\subsection{Effects of time}

The influence of electrolysis time on the dye removal efficiency of electrocoagulation is shown in Figure-9. The removal efficiency was increased with the increase in treatment time. For a fixed current density, increased electrolysis time led to increases in anodic dissolution, concentration of metal ions, and their hydroxide flocs. However, after reaching the optimal time, removal efficiency remained constant. This might be due to the formation of hydroxide ions on the cathode. Thus, the solution's $\mathrm{pH}$ increases with the increase in treatment time, which in turn, reduces removal efficiency. Moreover, the increase in time was associated with elevated levels of consumption of both the energy and electrode, which suggests that retention time is a very essential variable through its economic impacts on the level of the applicability of the entire process $[2,21,22,27,28]$.

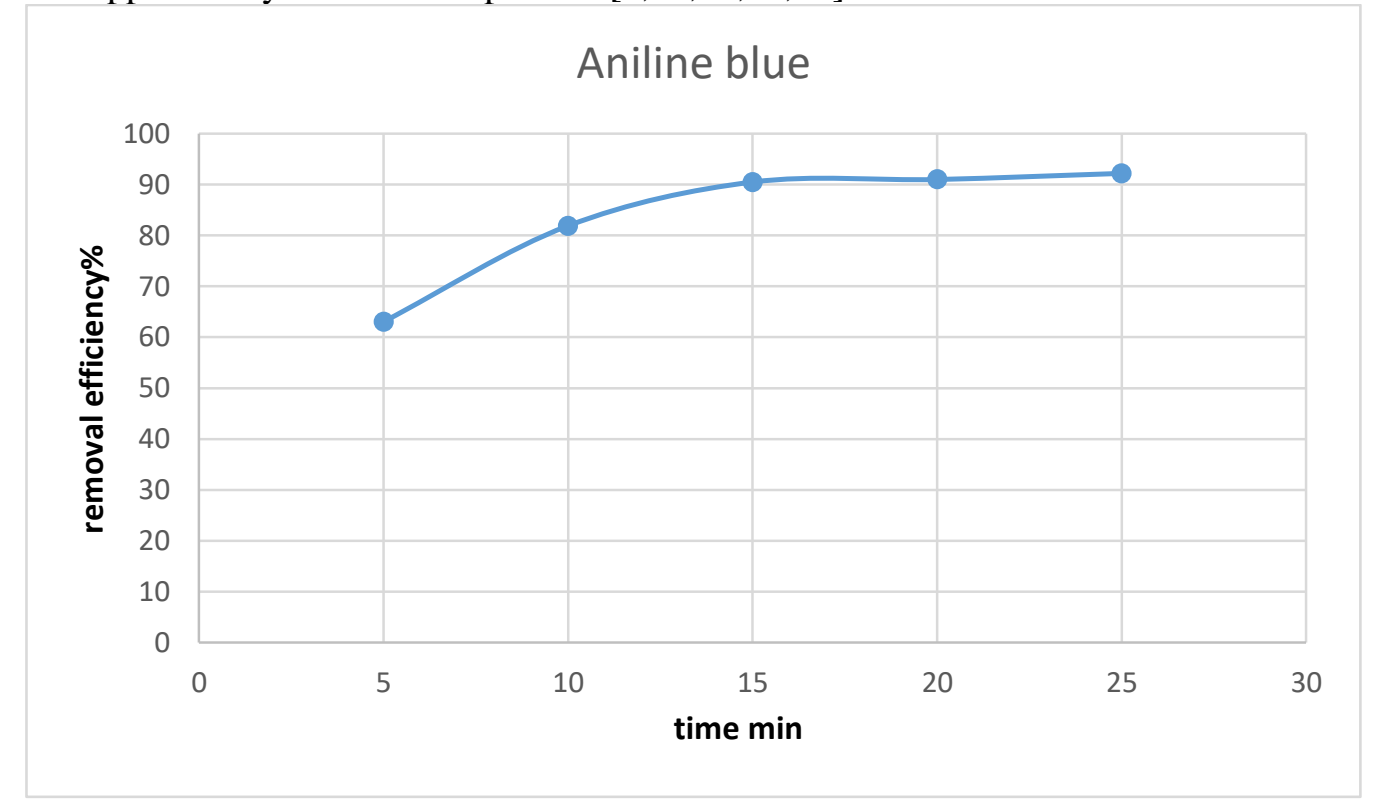

Figure 9-Effect of contact time on the percent removal of aniline blue dye. Current density 20 $\mathrm{mA} / \mathrm{cm} 2$ at $20 \pm 2^{\circ} \mathrm{C}, \mathrm{pH}=7$, dye conce. $50 \mathrm{ppm}$, salt conc. $462 \mathrm{ppm}$, and distance between electrodes $1.75 \mathrm{~cm}$. 


\section{Electrocoagulation isotherm}

Adsorption isotherm is a mathematical model with equations used to describe the relationship between the adsorbed and the absorbent materials.

The adsorption isotherms are often used for the determination of maximum capacities for setting pollutants and for the identification of the adsorption type.

Freundlich, Langmuir, Temkin, sips and Dubinin are the most frequent types used to determine the model.

Based on Langmuir isotherm, the plot of $1 / \mathrm{qe}$ versus $1 /$ Ce gives the constant values of $\mathrm{kl}$ and $\mathrm{qm}$ with the coefficient of determination $\left(\mathrm{R}^{2}\right)$, as shown in Figure- 10 and Table- 3 . The observed data did not agree with Langmuir isotherm according to $\mathrm{R} 2$ value.

In the assumption of Freundlich and Sips isotherms, regression analyses using Gauss-Newton's method was adopted to find the values of the constants which achieve the results and assure that the adsorption fits with Freundlich and Sips adsorption isotherms, with R2 value of 0.90 and 0.87 , respectively.

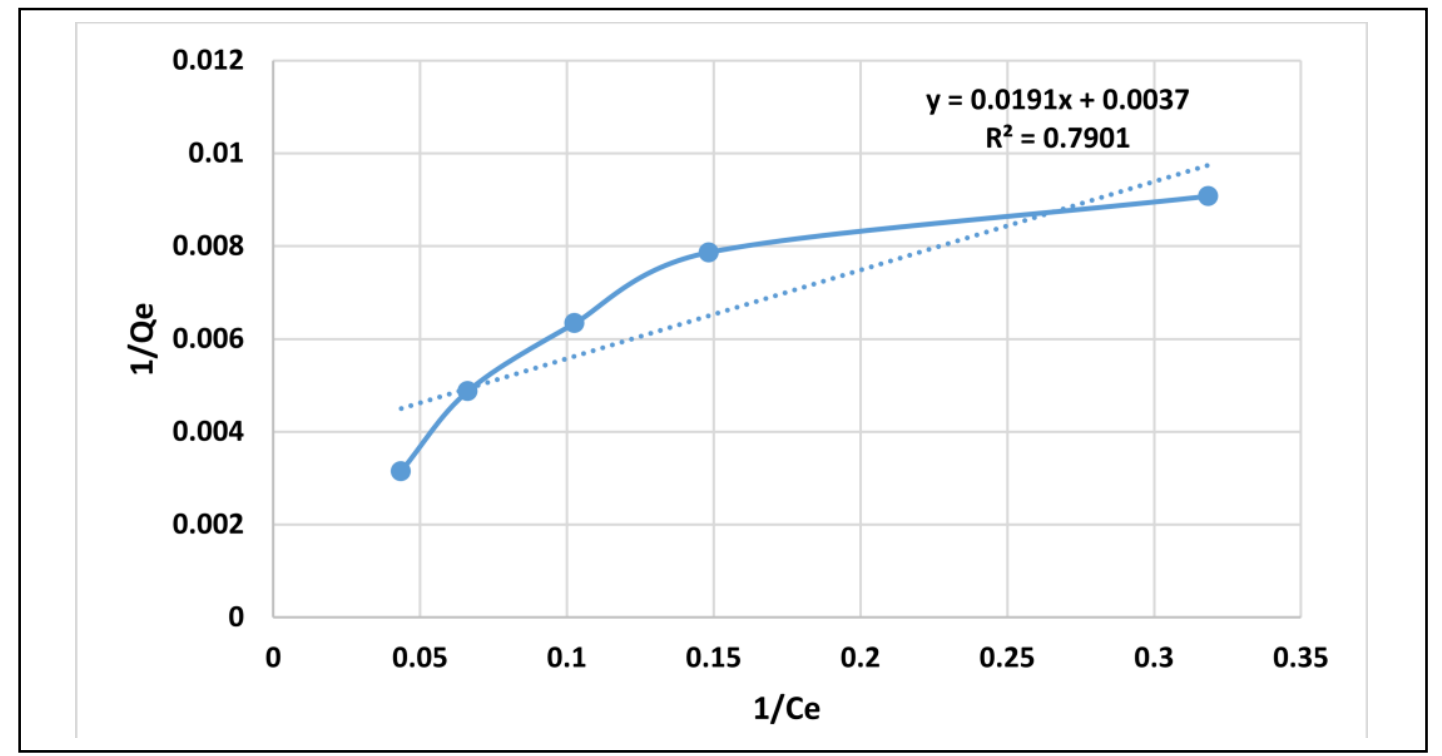

Figure 10-Adsorption data using langmiur isotherm.

Table 3-The adsorption isotherm parameters for aniline blue removal

\begin{tabular}{|c|c|c|c|}
\hline & & Langmuir & $\frac{1}{q e}=\frac{1}{Q 0}+\frac{1}{b Q 0 C e}$ \\
\hline & & $q_{\text {e }} \underline{(\mathrm{mg} / \mathrm{g})}$ & 270.2703 \\
\hline & & b $(\mathbf{L} / \mathbf{m g})$ & 0.19372 \\
\hline & & $\mathbf{R}^{2}$ & 0.79 \\
\hline & & Freundlich & $\ln q_{e}=\ln K_{F}+1 / n \ln C_{e}$ \\
\hline & & $\mathbf{n}$ & 1.92123 \\
\hline & & $K_{\mathrm{f}}(\mathbf{L} / \mathbf{m g})$ & 53.2288 \\
\hline & & $\mathbf{R}^{2}$ & 0.90 \\
\hline & & Sips & $q_{e}=\left(q_{s} K_{s} C_{e}^{1 / m}\right) /\left(1+K_{s} C_{e}^{1 / m}\right)$ \\
\hline & & $\mathrm{q}_{\mathrm{s}} \underline{\underline{\mathrm{mg}} / \mathrm{g})}$ & 317.39 \\
\hline & & $\mathrm{K}_{\mathrm{s}}(\mathbf{L} / \mathbf{m g})$ & 0.064 \\
\hline & & $\mathbf{m}$ & 1.344 \\
\hline & & $\mathbf{R}^{2}$ & 0.87 \\
\hline & & temkin & $Q e=B \ln \left(K_{T}\right)+B \ln (C e)$ \\
\hline
\end{tabular}




\begin{tabular}{|c|c|}
\hline $\mathrm{B} \underline{(\mathrm{J} / \mathrm{mol})}$ & 107.01 \\
\hline $\mathrm{K}_{\mathrm{T}}(\mathrm{L} / \mathrm{g})$ & 0.62282 \\
\hline $\mathbf{R}^{2}$ & 0.77 \\
\hline Dubinin & $q_{e}=q_{D} \exp \left(-B_{D}\left\{R T \ln \left(1+1 / C_{e}\right)\right\}^{2}\right)$ \\
\hline $\begin{array}{l}\mathbf{B}_{\mathbf{D}}\left(\mathbf{m o l}^{2}\right. \\
\left.\mathbf{J}^{-2}\right) \\
\end{array}$ & 1.59815E-06 \\
\hline $\mathrm{q}_{\mathrm{D}} \underline{\underline{(\mathrm{mg} / \mathrm{g})}}$ & 211.727 \\
\hline $\mathbf{R}^{2}$ & 0.52 \\
\hline
\end{tabular}

\section{Electrocoagulation kinetics}

The present study applied 3 models (pseudo first order, pseudo second order and Elovich equation) to investigate the adsorption kinetics of aniline blue dye. Correlation coefficient (R2) was used to express the conformity between the kinetic models and the experimental data.

Kinetic plots are presented in Figures- 11 and 12. The plot of $\ln$ (qe-qt) versus time gives a straight line for the pseudo first order (PFO), while (t/qt) versus time plot gives the pseudo second order's (PSO) representation and its linear parameters.

From R2 values of the two figures, it is clearly found that the adsorption process follows the pseudo second order (PSO) kinetics.

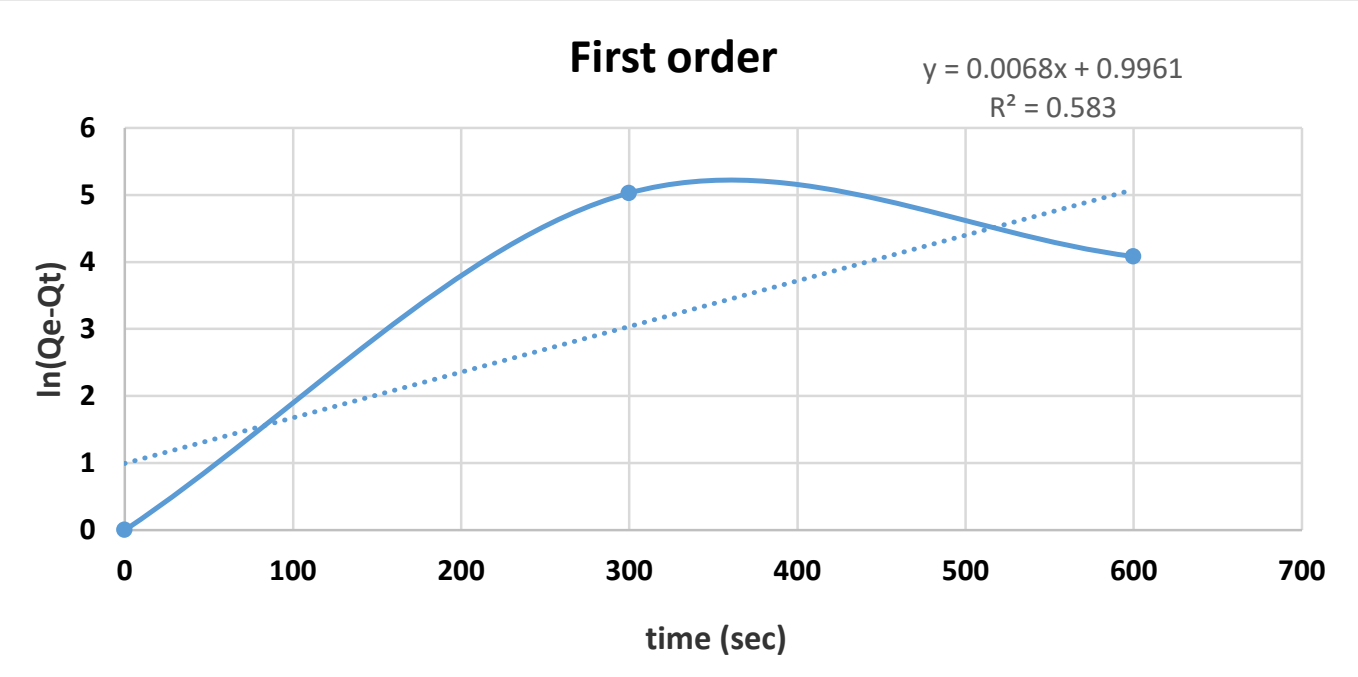

Figure 11-Pseudo first order plot of aniline blue

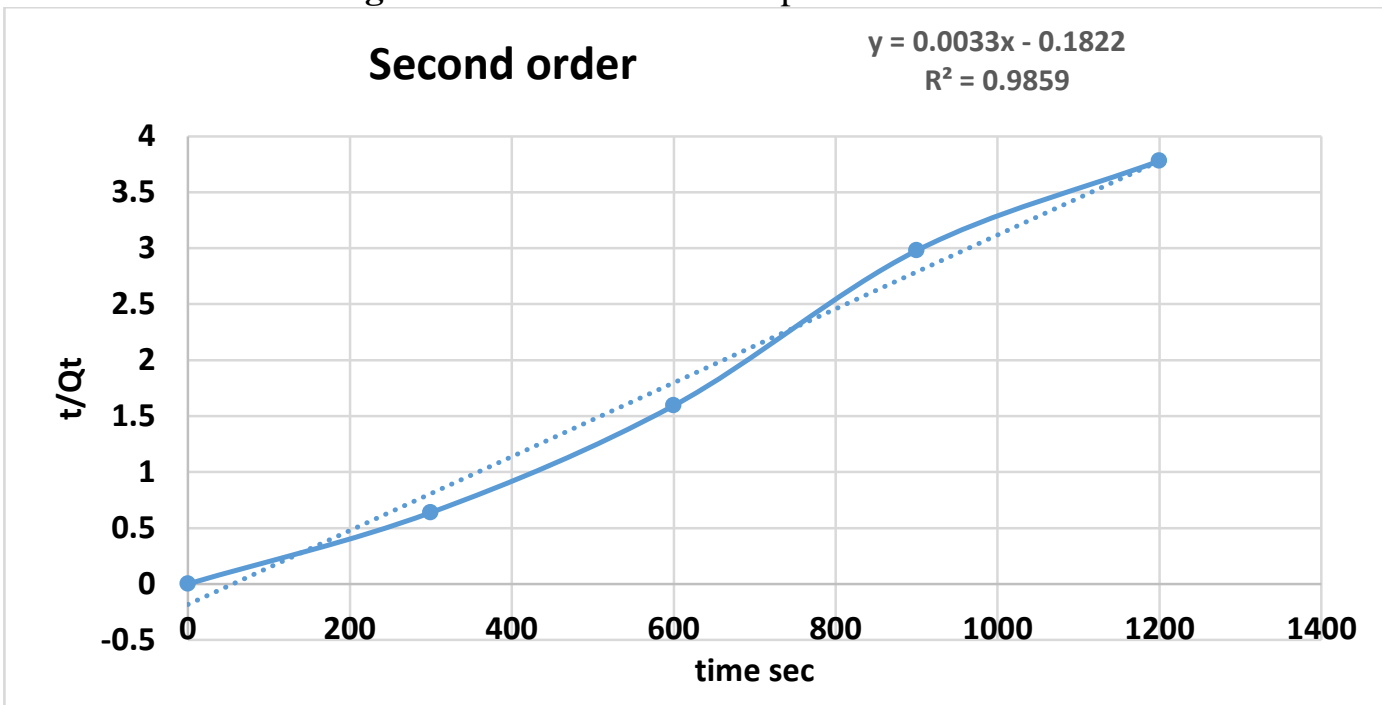

Figure 12-Pseudo second order plot of aniline blue. 


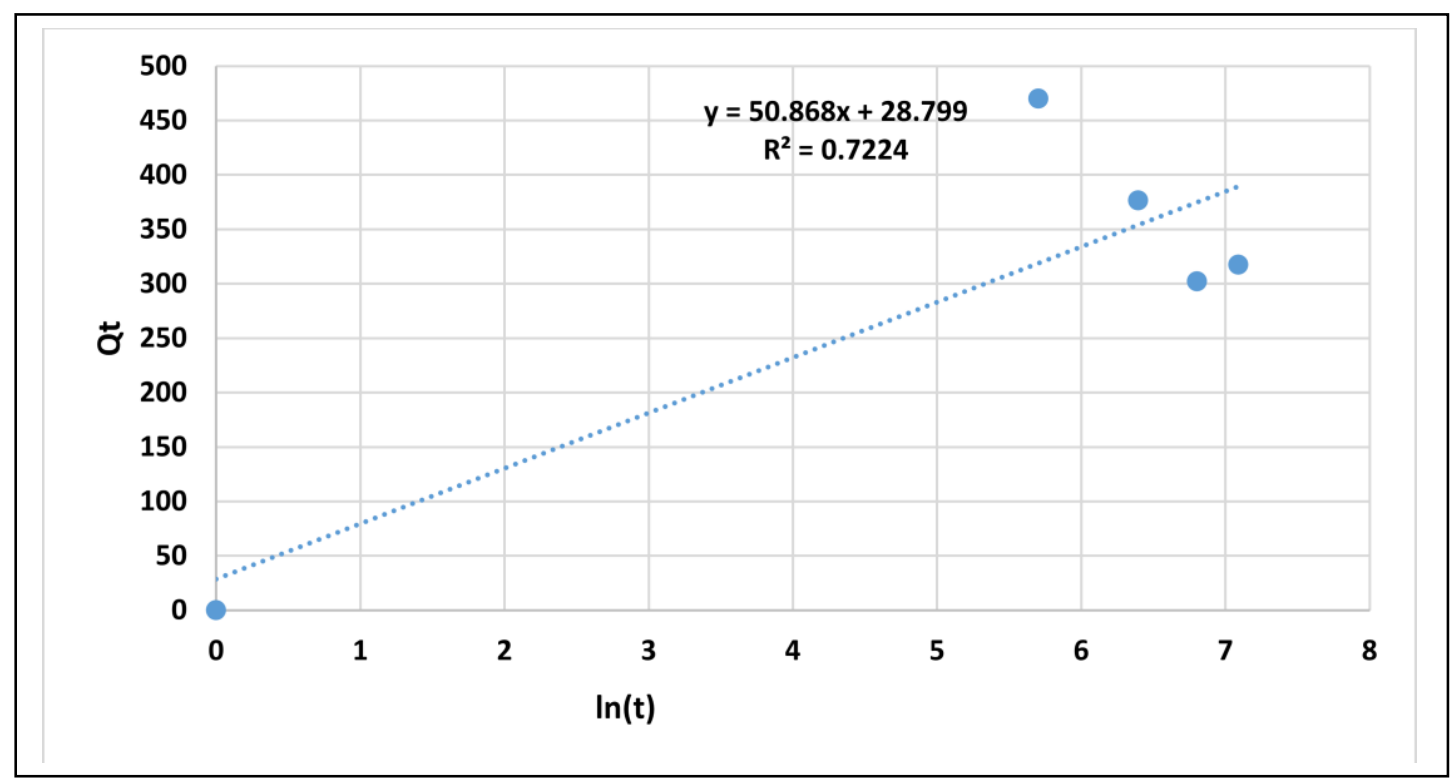

Figure 13-Elovich's plot of aniline blue.

Table 4-Kinetic parameters with R2 for aniline blue

\begin{tabular}{|c|c|}
\hline \multicolumn{2}{|l|}{ First order } \\
\hline$q_{e}(\mathbf{m g} / \mathbf{g})$ & 2.7074 \\
\hline$K_{I} \underline{\min }^{-1}$ & 0.0068 \\
\hline $\mathbf{R}^{2}$ & 0.58 \\
\hline \multicolumn{2}{|c|}{ Second order } \\
\hline$q_{e}(\mathbf{m g} / \mathbf{g})$ & 303.03 \\
\hline $\begin{array}{l}K_{I} \\
(\mathbf{g} / \mathbf{m g} . \mathbf{m i n})\end{array}$ & $-5.97695 \mathrm{E}-05$ \\
\hline $\mathbf{R}^{2}$ & 0.98 \\
\hline \multicolumn{2}{|c|}{ Elovich's equation } \\
\hline $\boldsymbol{\beta}$ & 0.019658725 \\
\hline$\alpha$ & 89.60271763 \\
\hline
\end{tabular}

\section{Conclusions}

In this paper, central composite design was used to establish the most suitable conditions for removing aniline blue from aqueous solutions by EC. Maximum removal efficiency (96 \%) was obtained at a current density of $20 \mathrm{~mA} / \mathrm{cm} 2$, a distance between electrodes of $1.75 \mathrm{~cm}$, a salt concentration of $462.5 \mathrm{mg} / \mathrm{l}$, a dye concentration of $50 \mathrm{ppm}$, a pH value of 7, and a time period of 15 min. The results showed that time and current density are the most important parameters affecting the performance of electrocoagulation system. The adsorption isotherm can be described by the Sips and Freundlich equation which provided the best fitted experimental results as compared to equations from the other applied models. Also, the electrocoagulation results were modeled by applying the adsorption kinetics and demonstrated that the pseudo second order model was convincingly consistent with the experimental observations. 


\section{References}

1. Khemilaa,B., Merzouka,B., Chouderc,A., Zidelkhirb,R. and Leclercd,J.P.2018. Removal of a textile dye using photovoltaic electrocoagulation . Sustainable Chemistry and Pharmacy, 7: 2735.

2. Mohamed, M.S., Farah, J.Y, and Farrag, T.E. 2013. Enhanced removal of Methylene Blue by electrocoagulation using iron electrodes. Egyptian Journal of Petroleum , 22: 211-216

3. Dalvand, A., Gholami, M., Joneidi, A. and Mahmoodi, N.M. 2011. Dye Removal, Energy Consumption and Operating Cost of Electrocoagulation of Textile Wastewater as a Clean Process . Clean-Soil, Air, Water. 39(7): 665-672

4. Othmani, A. , Kesraoui, A. and Seffen, M. 2017. The alternating and direct current effect on the elimination of cationic and anionic dye from aqueous solutions by electrocoagulation and coagulation flocculation. Euro- Mediterr J Environ Integr , 2(1): 2-6

5. Merzouka, B., Gourichb, B. , Sekkic, A. , Madanid,K. , Viale,Ch. and Barkaoui M. 2009. Studies on the decolorization of textile dye wastewater by continuous electrocoagulation process. Chemical Engineering Journal ,149(2009): 207-214

6. Song, S., Yao, J., He,Z., Qiu, J. and Chen, j. 2008. Effect of operational parameters on the decolorization of C.I. Reactive Blue 19 in aqueous solution by ozone-enhanced electrocoagulation . Journal of Hazardous Materials ,152(2008): 204-210

7. Sengil , I.A. and Ozacar, M . 2009 .The decolorization of C.I. Reactive Black 5 in aqueous solution by electrocoagulation using sacrificial iron electrodes . Journal of Hazardous Materials, 161(2009): 1369-1376 Contents

8. Attia, H.G. 2013. Decolorization of direct blue dye by electrocoagulation process. Journal of Engineering and Development, 17(1): 1813- 7822

9. Adeogun, A.I. and Balakrishnan, R. B. 2016. Kinetics, isothermal and thermodynamics studies of electrocoagulation removal of basic dye rhodamine B from aqueous solution using steel electrodes. Journal of Electrochemical Science and Engineering.

10. Song, Sh., He, Zh., Qiu,J., Xu,L. and Chen, J. 2007. Separation and Purification Technology, 55(2): $238-245$

11. Corda, N.C. and Kini, M. S. 2018. A Review on Adsorption of Cationic Dyes using Activated Carbon. MATEC Web of Conferences ,144: 2022

12. Adeogun, A.I. and Balakrishnan, R. B. 2016. Kinetics, isothermal and thermodynamics studies of electrocoagulation removal of basic dye rhodamine B from aqueous solution using steel electrodes. Journal of Electrochemical Science and Engineering.

13. Shah, A.R., Tahir, H., Ullah, H.M.K. and Adnan, A. 2017. Optimization of Electrocoagulation Process for the Removal of Binary Dye Mixtures Using Response Surface Methodology and Estimation of Operating Cost. Open Journal of Applied Sciences, 7(9): 458-484

14. Nariyan, E., Aghababaei, A. and Sillanpä, M. 2017. Removal of pharmaceutical from water with an electrocoagulation process; effect of various parameters and studies of isotherm and kinetic. Separation and Purification Technology, 188: 266-281

15. Ghanim, A.N. and Ajjam, S.K. 2013. Modeling Of Textile Wastewater Electrocoagulation Via Adsorption Isotherm Kinetics. The Iraqi Journal For Mechanical And Material Engineering, 13(1) :49-62

16. Aleboyehb, A., Daneshvar, N. and Kasiri , M.B. 2008 . Optimization of C.I. Acid Red 14 azo dye removal by electrocoagulation batch process with response surface methodology . Chemical Engineering and Processing , 47(2008) : 827-832

17. Nawel, A., Farid, D., Belkacem, M., Jean-Pierre, L. and Khodir, M. 2015. Improvement of electrocoagulation-electroflotation treatment of effluent by addition of Opuntia ficus indica pad juice. Separation and Purification Technology, 144(2015): 168-176 Contents

18. Nourouzi M.M, Chuah, T.G and Choong, Th.S.Y. 2011. Optimisation of reactive dye removal by sequential electrocoagulation-flocculation method: comparing ANN and RSM prediction. Water Science \& Technology, 1889: 984-995

19. Bazrafshan, E., Mohammadi, L., Moghaddam, A.A. and Mahvi, A.H. 2015. Heavy metals removal from aqueous environments by electrocoagulation process-a systematic review. Journal of Environmental Health Science \& Engineering, 13(1). 
20. Ahlawat, R., Srivastava, V., Ch., Mall, I.D. and Sinha, Sh. 2008. Investigation of the Electrocoagulation Treatment of Cotton Blue Dye Solution using Aluminium Electrodes. Clean Soil, Air, Water, 36(10-11): 863-869.

21. Mall, I.D., Taneja, N. and Thakur, Ch.K. 2013 .Treatment of Indigo Carmine Dye Bearing Wastewater by Electrocoagulation. 2nd International Conference on Environment, Agriculture and Food Sciences: 86-90.

22. Abu Ghalwa, N. M., Saqer, A.M. and Farhat, N.B. 2015. Removal of Reactive Red 24 Dye by Clean Electrocoagulation Process Using Iron and Aluminum Electrodes . Journal of Chemical Engineering \& Process Technology, 2(4): 1-7

23. Amani-Ghadima, A.R., Aber, S., Olad, A. and Ashassi-Sorkhabid, H. 2013. Optimization of electrocoagulation process for removal of an azo dye using response surface methodology and investigation on the occurrence of destructive side reactions. Chemical Engineering and Processing, 64(2013): 68-78

24. Salih,W.M., Alnasri, S.K. and Al Abdalaali , A.A. 2012 . Removal of Boron from Simulated Iraqi Surface Water by Electrocoagulation Method . Journal of Engineering, 18(11).

25. Khandegar, V. and Saroha, A.K. 2013 . Electrocoagulation for the treatment of textile industry effluent e A review. Journal of Environmental Management, 128: 949-963 .

26. Baskar, G., Pavithra, S.K., Fahad, K.Sh. and Renganathan S. 2013 . Optimization, equilibrium, kinetic modeling, and thermodynamic studies of biosorption of aniline blue by the dead biomass of Aspergillus fumigatus. Desalination and Water Treatment, 52: 19-21

27. Aoudja, S., Khelifab, A., Drouichea, N., Hecinia, M. and Hamitouche, H. 2010. Electrocoagulation process applied to wastewater containing dyes from textile industry. Chemical Engineering and Processing, 49(11): 1176-1182 Contents.

28. Hameed, B.H. and Ahmad, A.A. 2009. Batch adsorption of methylene blue from aqueous solution by garlic peel, an agricultural waste biomass. Journal of Hazardous Materials , 164(2009): 870-875 Contents 